\title{
Too-low magnetic inclinations in central Asia: an indication of a long-term Tertiary non-dipole field?
}

\author{
Jingwei Si and Rob Van der Voo* \\ Department of Geological Sciences, the University of Michigan, Ann Arbor, MI 48109-1063, USA
}

\begin{abstract}
Observed Tertiary palaeolatitudes in central Asia are more southerly (by about $1600 \mathrm{~km}$ on average) than those predicted from the Eurasian reference palaeopoles. Subsequent northward displacements of the central Asian terranes are unlikely to have been this large. In this study we analyse to what extent non-dipole fields, especially octupole fields, can explain this phenomenon. A global (zonal) octupole field manifests itself in two ways. (1) Because the reference APWP is based mostly on results from the UK and North America, its palaeopoles will be far-sided as seen from the North Atlantic, but near-sided as seen from eastern Asia, giving predicted palaeolatitudes that
\end{abstract}

are too high. (2) An octupole field contribution produces observed palaeolatitudes, as calculated with the dipole formula for central Asia, that are too low. Both effects therefore increase the palaeolatitude anomalies in Asia. We find that an octupole/dipole field ratio (G3) of 0.06 or greater will reduce the palaeolatitude discrepancies significantly and is of the same magnitude as the G3 estimate of a recent analysis of Early Tertiary European and North American data.

Terra Nova, 13, 471-478, 2001

\section{Introduction}

It has repeatedly been observed during the last decade that latest Cretaceous and Tertiary palaeomagnetic inclinations are anomalously low in central Asia (e.g. Westphal, 1993; Thomas et al., 1994; Chauvin et al., 1996; Cogné et al., 1999, and references therein), when compared to the reference Apparent Polar Wander Path (APWP) for Eurasia (e.g. Besse and Courtillot, 1991). The observed palaeolatitudes of central Asian terranes are thus more southerly, by some $15^{\circ}$ on average, than those predicted by Eurasian palaeopoles. Figure 1 plots the differences between observed palaeolatitudes of the central Asian results (Fig. 2) used in this study and their predicted palaeolatitudes from a reference APWP. It does not make a significant difference whether our own APWP, to be discussed below, is used, or whether a published APWP is used. Chauvin et al. (1996) have noted that there is a general tendency for the magnitude of the palaeolatitude anomalies to increase from southeastern Europe to China. A subset of our own data set, restricted to sites in a present-day latitude band of $31-39^{\circ}$, also shows this trend (Fig. 3), al-

*Correspondence: Rob Van der Voo, Department of Geological Sciences, the University of Michigan, Ann Arbor, MI 48109-1063, USA. E-mail: voo@umich. edu; fax: +1 734763 4690; tel.: + 1734 7648322 . though for the entire data set such a trend is less evident.

Several explanations have been proposed for these puzzling discrepancies, and these have been summarized by Cogné et al. (1999). (1) Inadequate demagnetization may have led to palaeomagnetic inclinations that are too shallow because of contaminations by overprints. (2) The observed palaeolatitudes are accurate and reflect large subsequent northward movements of the sampling areas. (3) The reference APWP may be incompletely determined or based on flawed palaeopoles. (4) The reference APWP may be inappropriate for Siberia. Siberia, as the craton to the north of the central Asian terranes, may itself have moved relative to the European sites where the palaeopoles were obtained. (5) The palaeolatitudes of sedimentary rocks may be inaccurate because of inclination shallowing due to depositional processes or compaction. (6) Global or local non-dipole fields may render the palaeomagnetically determined palaeolatitudes inaccurate.

All of these possible causes may have conspired to produce the discrepancies, although some are more likely than others. Most of the

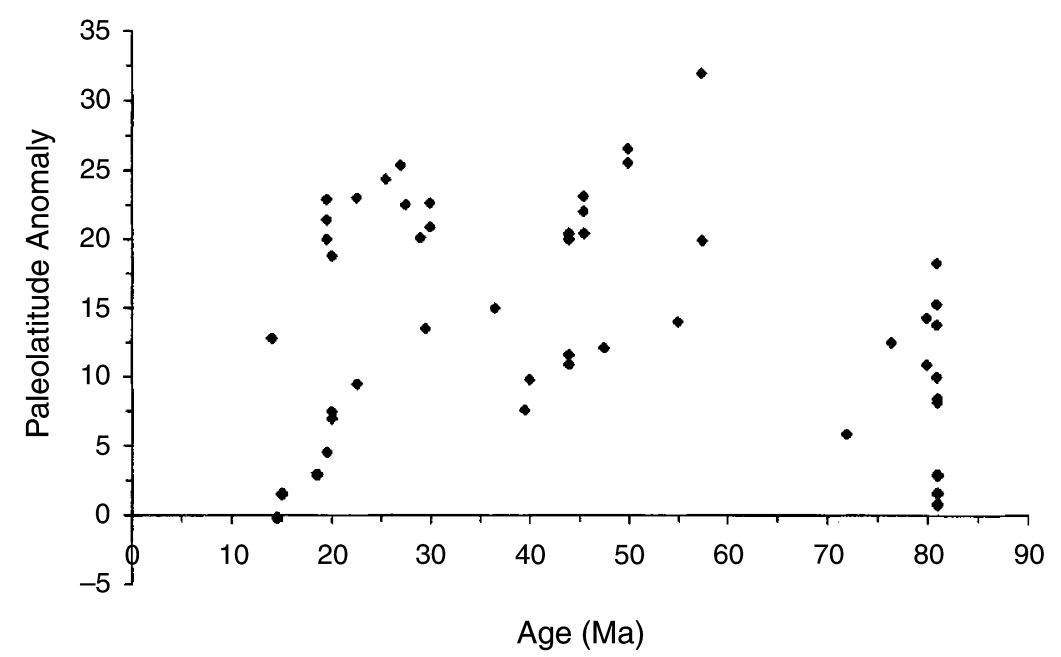

Fig. 1 Palaeolatitude anomalies (calculated as the difference between predicted and observed values) of central Asian sites plotted as a function of time. The predicted palaeolatitudes are calculated for the site locations (in Table 1) from the mean palaeopoles of Table 3 . 


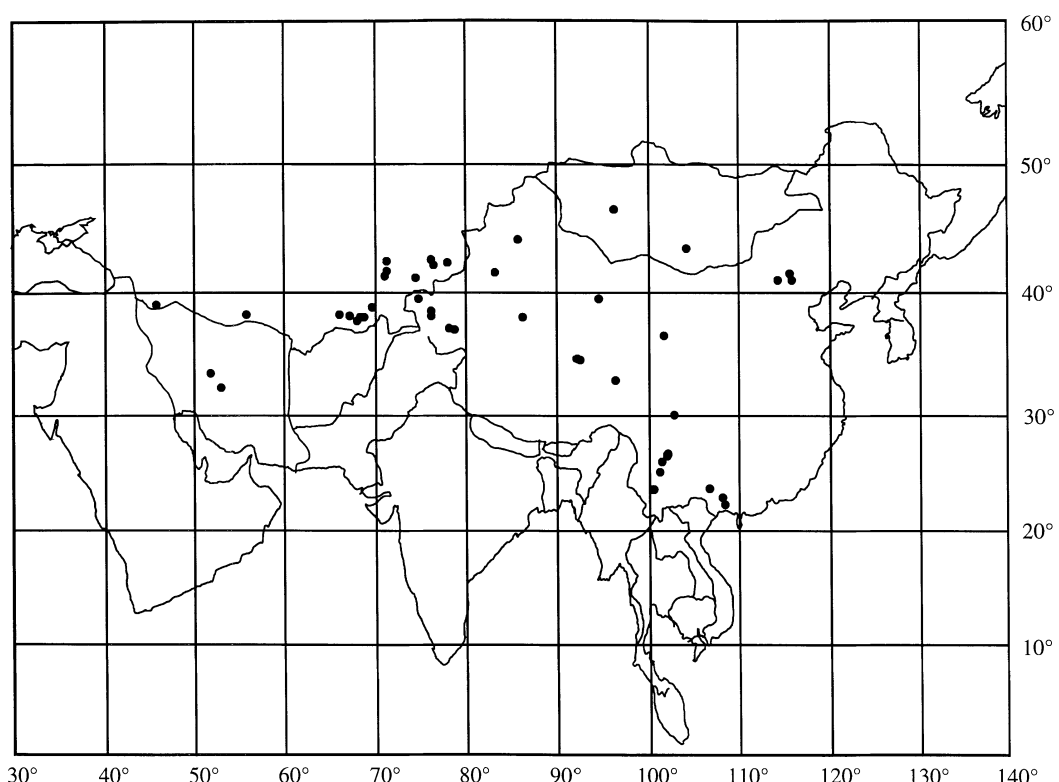

Fig. 2 Location map of the Asian sites, as listed in Table 1.

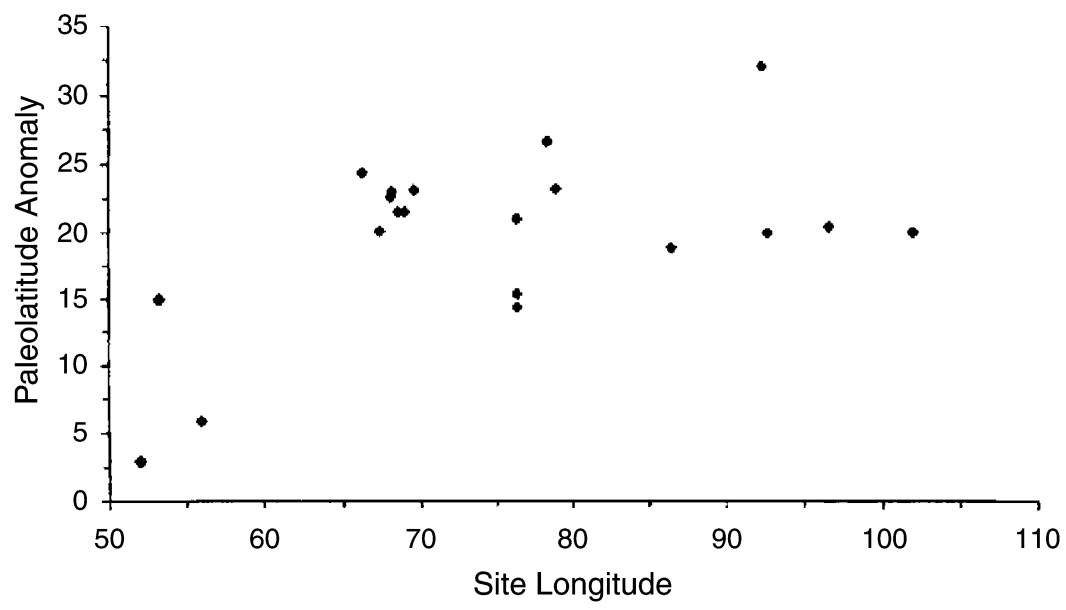

Fig. 3 Palaeolatitude anomalies (calculated as the difference between predicted and observed values, as in Fig. 1) of selected central Asian sites plotted as a function of site longitude. Only sites located between 31 and $39^{\circ}$ latitude have been included.

results appear to have been obtained by thorough demagnetization and are supported by convincing field tests, so poor demagnetization techniques likely cannot be blamed for all of the anomalies in the entire dataset. Some northward movement of terranes with respect to Siberia, subsequent to magnetization acquisition, is very likely, but there is a consensus that the magnitude of these displacements has been much less than the $1600 \mathrm{~km}$, on average, that could be inferred from the palaeomagnetic results. Most studies describing the palaeolatitude anomalies used the reference APWP of Besse and Courtillot (1991), and there is no reason to suspect the validity of this APWP for Europe or North America. As we will show below, using a differently constructed reference APWP based on results from North-Atlantic-bordering continents only does not change the analysis. However, the absence of palaeopoles for Siberia means that a 'Eurasian' APWP of necessity is unsatisfactory if relative movements took place between Siberia and Eur- ope, as suggested by Cogné et al. (1999). We note, however, that the palaeolatitude discrepancies appear to remain of similar magnitude from $80 \mathrm{Ma}$ through at least $25 \mathrm{Ma}$ (Fig. 1), implying that these relative movements must have taken place in the Miocene or later, for which there is little evidence. As acknowledged by Cogné and co-workers, the locations of the necessary extensional movements, whether in a discrete or a distributed zone, are very speculative, and the whole hypothesis merely replaces a tectonic enigma within central Asia by another presumably to be placed somewhere near the Urals or in eastern Europe.

Too-shallow inclinations because of sedimentary processes have been investigated experimentally by Tan et al. (1996) for rocks from Tarim; they found that the silt-sized fraction of the sediments did not show large enough inclination-shallowing effects, whereas the clay-sized fraction did. Most of the central Asian results are based on hematitic silt- or sandstones. The database contains a few igneous rocks (Thomas et al., 1994), which would not show the effects of inclination shallowing, but more results from extrusives are badly needed.

While we cannot exclude the possibility that the palaeolatitude anomalies are caused by inclination error, we find that the last possibility, namely a contribution from nondipole fields, is certainly also a possible solution. In recent years, attention has been refocused on non-dipole components in the longterm palaeomagnetic field (Kent and Smethurst, 1998; Van der Voo and Torsvik, 2001), but as a possible explanation for the central Asian palaeolatitude enigma, it was proposed already a decade ago by Westphal (1993). According to Chauvin et al. (1996), the Tertiary inclination anomaly progressively increases from $0^{\circ}$ on the Atlantic margin, to about $10^{\circ}$ in the eastern Mediterranean and Middle East, to reach a maximum of $25^{\circ}$ in central Asia. They proposed that this reflects a regional non-dipole field during the Tertiary, which at first glance is a very logical explanation. However, as we will show in this study, even a zonal (globally symmetric) non- 
dipole field can cause systematic anomaly trends as a function of longitude when a comparison with a reference APWP from a remote part of the world is involved.
Van der Voo and Torsvik (2001) tested for the existence of a zonal octupole field from Late Carboniferous through Early Tertiary by comparing the observed palaeomagnetic palaeolatitude distributions for the Laurentian and European landmasses with the patterns predicted from their mean palaeopoles. Their analysis did not provide information about

Table 1 Central Asian Sites

\begin{tabular}{|c|c|c|c|c|c|c|c|c|c|c|c|}
\hline Site & GPDB & Dc & $\alpha_{95}$ & Kd & Dec & Inc & Glat & Glon & Plat & Plon & Age \\
\hline Mengyejing Fm, Yunnan, China & 2927 & 4 & 7.9 & 10.3 & 42.8 & 26.1 & 23.5 & 100.8 & 48.5 & 196.5 & 14 \\
\hline Mongolian Basalts, Mongolia & 2815 & 3 & 14 & 45 & 18 & 67 & 46.5 & 96.5 & 77 & 162 & 14.5 \\
\hline Hannduba Fm, Inner Mongolia and Hebei & 2190 & 4 & 4.2 & 24.4 & 8.2 & 61.5 & 41 & 114.7 & 83.4 & 192.8 & 15 \\
\hline Hassan-Abad Series, Iran & 1802 & 3 & 12 & 28 & 344.5 & 49 & 33.4 & 52 & 76.4 & 311.1 & 18.5 \\
\hline Tajik Depression Sediments, Tajikistan & 2874 & 4 & 12 & 30 & 336 & 30 & 37.7 & 68.2 & 60 & 299 & 19.5 \\
\hline Tajik Depression Sediments, Tajikistan & 2874 & 4 & 9 & 25 & 310 & 33 & 38 & 69 & 42 & 328.5 & 19.5 \\
\hline Tajik Depression Sediments, Tajikistan & 2874 & 4 & 13 & 16 & 349 & 35 & 38.1 & 67.4 & 69 & 277.5 & 19.5 \\
\hline Dzhety-Ogyuz Fm, N.Tien Shan & 2814 & 4 & 9 & 97 & 357 & 59 & 42.2 & 76.7 & 86.7 & 300.6 & 19.5 \\
\hline Tajik Depression Sediments, Tajikistan & 2874 & 4 & 15 & 26 & 347 & 33 & 38 & 68.6 & 67 & 282 & 19.5 \\
\hline Hannuoba Basalt Fm, Inner Mongolia & 2785 & 4 & 6.1 & 47 & 358.5 & 59 & 41 & 116.2 & 88.6 & 29.2 & 20 \\
\hline Tertiary Basalts, Inner Mongolia & 2526 & 4 & 6.1 & 47 & 358.5 & 59 & 41.5 & 116 & 88.6 & 29.2 & 20 \\
\hline Jianglisai, Altyn Tagh fault & [¹] & & 6.7 & & 358.4 & 39.6 & 38 & 86.5 & 74.4 & 272 & 20 \\
\hline Sanhaogou Fm, Yunnan, China & 2927 & 4 & 7.5 & 15.3 & 21.1 & 35.5 & 23.5 & 100.7 & 70 & 197.8 & 22.5 \\
\hline Tajik Depression Sediments, Tajikistan & 2874 & 4 & 11 & 19 & 317 & 33.5 & 38.8 & 69.6 & 47.5 & 323 & 22.5 \\
\hline Middle Cenozoic Redbeds, Tajikistan & 3085 & 4 & 9.7 & 19.1 & 3.4 & 29.6 & 38.2 & 66.3 & 67.4 & 237.7 & 25.5 \\
\hline Massaget Fm, Uzbekistan & 2814 & 4 & 9 & 33 & 342 & 34 & 41.3 & 71.3 & 62.6 & 290.8 & 27 \\
\hline Tajik Depression Sediments, Tajikistan & 2874 & 4 & 11 & 7 & 312 & 32 & 37.7 & 68.1 & 43.5 & 326 & 27.5 \\
\hline Dzhety-Ogyuz Fm,N.Tien Shan,Kyrgyzstan & 2814 & 4 & 11 & 50 & 0 & 44 & 42.4 & 78.2 & 73.4 & 258.2 & 29 \\
\hline Mongolian Basalts, Central Mongolia & 2815 & 3 & 8 & 19 & 25 & 56 & 43.5 & 104.5 & 70 & 204 & 29.5 \\
\hline Aertashi, Altyn Tagh fault & [*1] & & 5 & & 17.6 & 36.9 & 38.1 & 76.4 & 66.8 & 210.5 & 30 \\
\hline Subei, Altyn Tagh fault & {$\left[{ }^{*} 1\right]$} & & 6.6 & & 344.7 & 39.7 & 39.5 & 94.8 & 68.6 & 316.8 & 30 \\
\hline Kuh-e-kaleh-e-kargushi Series, Iran & 1802 & 3 & 5.9 & 112 & 61 & 34.2 & 32.2 & 53.2 & 34.2 & 141.2 & 36.5 \\
\hline Mengla Group, Yunnan, China & 2927 & 4 & 7.6 & 12 & 84.7 & 38.9 & 23.5 & 100.7 & 13.2 & 172.2 & 39.5 \\
\hline Armenian Sandstones, Armenia & 2817 & 3 & 12 & 7.8 & 8 & 49 & 39 & 46 & 78 & 190 & 40 \\
\hline Talas Basin Sediments, Kirgisistan & 2814 & 4 & 22 & 20 & 343 & 54 & 42.5 & 71.5 & 74.5 & 316.1 & 44 \\
\hline Chaktal Basin Sediments, Uzbekistan & 2814 & 4 & 9 & 25 & 352 & 42 & 41.7 & 71.5 & 71.3 & 274.8 & 44 \\
\hline Eocene Red Bed, Xining, Qaidam & [*2] & & 13.2 & 34.8 & 29.3 & 40.8 & 36.5 & 102 & 61.6 & 211.3 & 44 \\
\hline Fenghuanshan Fm, Guangxi, China & 2785 & 4 & 4.3 & 36.3 & 5 & 34 & 22.8 & 108.4 & 83.8 & 236 & 44 \\
\hline Naryn Redbeds, Kyrgyzstan & 2814 & 4 & 11 & 13 & 5 & 37 & 41.2 & 74.7 & 69 & 241.5 & 45.5 \\
\hline Eocene Red Bed, Xialaxiu, Qiangtang & [²] & & 9.5 & 26.8 & 322 & 32.3 & 32.8 & 96.6 & 52.6 & 352 & 45.5 \\
\hline Lower Tertiary Limestones and Redbeds, Tarim & {$\left[{ }^{*} 3\right]$} & & 13.3 & 34 & 27.8 & 30 & 37 & 79 & 58.1 & 202 & 45.5 \\
\hline Liuchou and Nadu Fm, Guangxi, China & 2738 & 4 & 6.5 & 31.5 & 325.5 & 33.2 & 23.6 & 107 & 58.6 & 18.2 & 47.5 \\
\hline Leidashu Fm, Sichuan, China & 2497 & 4 & 12.1 & 25.7 & 358.7 & 13.7 & 26.4 & 102.3 & 70.6 & 286.1 & 50 \\
\hline Puska, Altyn Tagh fault & [*1] & & 8.4 & & 4.3 & 24.3 & 37.1 & 78.4 & 65.3 & 248.3 & 50 \\
\hline Kokturpak Fm, Kyrgyzstan & 2814 & 4 & 10 & 48 & 10 & 49 & 42.6 & 76.4 & 75 & 220.9 & 55 \\
\hline Fenghuoshan Group, Qiangtang & 3228 & 4 & 6 & 32.7 & 25.5 & 34.6 & 34.5 & 92.7 & 62.6 & 210.5 & 57.5 \\
\hline Fenghuoshan Group, Qiangtang & 1962 & 4 & 7.2 & 29 & 9 & 14 & 34.6 & 92.4 & 61 & 253 & 57.5 \\
\hline Limestones and marls, Turkmenistan & 1810 & 3 & 2.6 & 526 & 12 & 45 & 38.2 & 56 & 74 & 193 & 72 \\
\hline Xiaoba, Leidashu Fm, Sichuan, China & 1403 & 4 & 8.6 & 26.7 & 357.6 & 31.6 & 26.5 & 102.3 & 80.8 & 296.8 & 76.5 \\
\hline Douggou and Ziniquan Fm, Junggar & 2385 & 4 & 6.9 & 56.9 & 12.5 & 51.3 & 44.2 & 86 & 74.3 & 223.1 & 80 \\
\hline Yingjisha, Altyn Tagh fault & [*1] & & 9.9 & & 7.6 & 37.1 & 38.1 & 76.4 & 71.4 & 233.6 & 80 \\
\hline Yingjisha Sediments, Tarim & 2661 & 4 & 9.9 & 46.6 & 7.6 & 37.1 & 38.5 & 76.4 & 71 & 234 & 81 \\
\hline Wuqia Sediments, Tarim & 2661 & 4 & 7.4 & 39.5 & 11 & 40 & 39.5 & 75 & 70.8 & 222.6 & 81 \\
\hline Bashenjiqike Fm, Tarim & 1714 & 4 & 8.6 & 114 & 16.3 & 39.2 & 41.6 & 83.5 & 66.3 & 222.9 & 81 \\
\hline Xiaoba Fm, Sichuan, China & 2497 & 4 & 6.6 & 28.8 & 8.1 & 38.8 & 26.5 & 102.4 & 81.5 & 220.9 & 81 \\
\hline Matoushan Fm, Yunnan, China & 2575 & 4 & 14.3 & 12.4 & 45.6 & 46.6 & 25 & 101.5 & 49.3 & 177.1 & 81 \\
\hline Jiangdihe Fm, Yunnan, China & 3219 & 4 & 3.5 & 77.9 & 26.9 & 35.6 & 25.9 & 101.7 & 64.5 & 200.2 & 81 \\
\hline Upper Series Deposits, Guangxi, China & 2738 & 4 & 9.3 & 31.7 & 349.3 & 35.3 & 22.2 & 108.7 & 79.4 & 7.1 & 81 \\
\hline Upper Cretaceous Redbeds,Sichuan,China & 2711 & 3 & 3.9 & & 359 & 51.6 & 29.9 & 103.1 & 88.1 & 75.7 & 81 \\
\hline Xiaobu Fm, Sichuan, China & 2713 & 3 & 5.3 & & 12.6 & 46.2 & 26.6 & 102.4 & 78.9 & 186.6 & 81 \\
\hline
\end{tabular}

$\mathrm{Fm}=$ Formation; GPDB = Global Palaeomagnetic Data Base Reference Number (REFNO in Lock and McElhinny (1991); Dc = Demag Code (5 is the best score); $\alpha_{95}$ and $\mathrm{Kd}$ are the radius of the cone of $95 \%$ confidence and precision parameter, respectively; Dec and Inc are declination and inclination (in degrees); Glat $=$ Site's latitude; Glon = Site's longitude; Plat = Palaeopole's latitude; Plon = Palaeopole's longitude; Age in million years. Additional references to Table 1 (not in GPDB): [*1] Rumelhart et al. (1999), [*2] Cogné et al. (1999), [³] Gilder et al. (1996). 
Table 2 Eurasian reference palaeopoles

\begin{tabular}{|c|c|c|c|c|c|c|c|c|c|}
\hline Age (Ma) & $\mathrm{Dc}(\mathrm{Q})$ & GPDB & Dec & Inc & $\alpha_{95}$ & GLat & GLon & Plat & Plon \\
\hline 2.5 & 3 & 1275 & 339.91 & 55.32 & 14.4 & 35.32 & 255.1 & 73.68 & 172.85 \\
\hline 3.5 & 4 & 2863 & 357.23 & 49.42 & 3.6 & 36.21 & 255.71 & 83.62 & 97.8 \\
\hline 5 & 3 & 846 & 13.08 & 63.06 & 9.2 & 50 & 13.3 & 79.6 & 130 \\
\hline 5.5 & 3 & 1275 & 17.33 & 51.53 & 9.7 & 35.62 & 255.01 & 75.23 & 353.48 \\
\hline 8 & 3 & 56 & 1.51 & 61.3 & 12.9 & 48 & 9 & 84.3 & 177.7 \\
\hline 15.5 & 3 & 2288 & 5.48 & 56.5 & 12.9 & 46.54 & 253.33 & 79.69 & 48.14 \\
\hline 16.5 & 4 & 2426 & 358.6 & 63.98 & 5.2 & 50.5 & 9.4 & 85.1 & 200.9 \\
\hline 22.5 & 4 & 1402 & 4.72 & 55.01 & 6.7 & 38.36 & 261.13 & 85.29 & 26.52 \\
\hline 23 & 3 & 1300 & 347.78 & 65.3 & 8.4 & 39.8 & 259.34 & 78.37 & 214.06 \\
\hline 23.5 & 4 & 1299 & 350.79 & 53.7 & 5.2 & 38.56 & 261.24 & 81.43 & 143.83 \\
\hline 24 & 4 & 3282 & 14.11 & 62 & 4.4 & 50.8 & 8 & 77.8 & 130.8 \\
\hline 25.5 & 4 & 1402 & 332.93 & 54.28 & 8.6 & 38.36 & 261.13 & 68.06 & 170.18 \\
\hline 26 & 4 & 3130 & 348.86 & 55.65 & 6.8 & 38.97 & 261.05 & 80.75 & 157.01 \\
\hline 27 & 4 & 2492 & 358.66 & 40.74 & 8.8 & 33.68 & 264.54 & 79.55 & 91.33 \\
\hline 27 & 4 & 1299 & 351.67 & 50.81 & 5.4 & 38.56 & 261.24 & 80.2 & 127.79 \\
\hline 28 & 3 & 2637 & 17.26 & 46.94 & 9.4 & 31.51 & 263.49 & 74.68 & 1.74 \\
\hline 28.5 & 4 & 2633 & 335.1 & 49.32 & 5 & 41.85 & 262.1 & 66.85 & 149.89 \\
\hline 30 & 4 & 1315 & 352.91 & 49.57 & 4.4 & 35.41 & 259.65 & 82.23 & 131.55 \\
\hline 30 & 3 & 2631 & 354.36 & 49.01 & 5 & 35.41 & 259.76 & 82.74 & 122.13 \\
\hline 33.5 & 3 & 1566 & 339.58 & 43.22 & 10.3 & 37.91 & 262.71 & 68.51 & 142.26 \\
\hline 33.5 & 3 & 311 & 0.12 & 63.44 & 7 & 50 & 17 & 85 & 196 \\
\hline 33.5 & 4 & 2400 & 0.38 & 51.84 & 5.5 & 50.65 & 254.66 & 71.81 & 73.63 \\
\hline 34 & 3 & 1506 & 1.06 & 60.21 & 3.4 & 50.3 & 7 & 80.8 & 182 \\
\hline 37 & 4 & 2943 & 351.11 & 51.13 & 4.3 & 31.42 & 265.37 & 82.42 & 180.66 \\
\hline 40 & 3 & 562 & 6.23 & 68.59 & 2.4 & 56.49 & 310.32 & 84.14 & 89.33 \\
\hline 44 & 3 & 1632 & 355.44 & 60.13 & 7.7 & 46.59 & 262.05 & 83.54 & 114.32 \\
\hline 47 & 3 & 87 & 6.82 & 56.64 & 9 & 40.4 & 292.82 & 83.81 & 51.54 \\
\hline 47 & 3 & 1865 & 1.6 & 60.59 & 10.1 & 40.39 & 293.03 & 88.31 & 338.2 \\
\hline 47 & 4 & 2560 & 336.77 & 63.88 & 5.6 & 50.18 & 256.64 & 73.82 & 159.02 \\
\hline 49.5 & 2(5) & 755 & 3.4 & 63.1 & 1.5 & 51.2 & 355.3 & 83 & 154.99 \\
\hline 50 & $2(6)$ & 340 & 352.27 & 58.14 & 4 & 55 & 356 & 73 & 197 \\
\hline 51 & 4 & 3150 & 350.74 & 54.07 & 4.9 & 46.2 & 262.42 & 76.45 & 116.82 \\
\hline 51 & 3 & 1270 & 351.66 & 66.28 & 2.6 & 52.48 & 263.32 & 83.49 & 140.98 \\
\hline 51 & 3 & 1348 & 346.13 & 60.98 & 4 & 50.84 & 261.61 & 77.04 & 134.17 \\
\hline 51 & $2(4)$ & 1174 & 3.4 & 66.77 & 2 & 57.1 & 354.1 & 82 & 158 \\
\hline 52 & 3 & 56 & 20.18 & 61.52 & 16 & 48 & 9 & 74.9 & 112.19 \\
\hline 52 & $2(5)$ & 1040 & 12.47 & 61.49 & 10 & 56.5 & 354.2 & 74 & 139 \\
\hline 53 & 4 & 2759 & 1.77 & 63.7 & 3.4 & 50.39 & 265.68 & 84.81 & 71.84 \\
\hline 53.5 & 3 & 83 & 356.16 & 63.31 & 2.7 & 56.6 & 353.8 & 78 & 187 \\
\hline 55 & $2(5)$ & 85 & 4.46 & 62.53 & 3.5 & 57.6 & 353.4 & 76 & 160 \\
\hline 56 & $2(4)$ & 654 & 4.55 & 54.82 & 5 & 55.1 & 353.9 & 70 & 163 \\
\hline 57 & $2(5)$ & 504 & 335.06 & 63.89 & 14 & 46.03 & 268.78 & 72.68 & 186.28 \\
\hline 57 & 3 & 419 & 355.51 & 68.87 & 6 & 62 & 353 & 80 & 189 \\
\hline 57 & 2(3) & 650 & 4.1 & 66.66 & 1.9 & 62 & 353 & 77 & 161.01 \\
\hline 57.5 & $2(3)$ & 86 & 3.48 & 58.8 & 2.5 & 57.4 & 353.7 & 72 & 165 \\
\hline 58 & 3 & 1204 & 1.02 & 60.02 & 2.7 & 56.9 & 353.8 & 74 & 171 \\
\hline 59 & 3 & 1638 & 342.05 & 52.44 & 17.7 & 52.34 & 264.93 & 66.76 & 125.83 \\
\hline 59 & $2(6)$ & 1169 & 358.71 & 65.79 & 2.4 & 57 & 353.5 & 81 & 179.02 \\
\hline 59.5 & 3 & 1377 & 359.62 & 62.38 & 2.7 & 56.7 & 353.8 & 77 & 175.01 \\
\hline 61 & 2(6) & 1033 & 348.05 & 51.43 & 3 & 43.84 & 266.37 & 74.97 & 128.92 \\
\hline 62 & $2(5)$ & 1055 & 2.33 & 57.82 & 2.8 & 56.4 & 353.9 & 72 & 167.99 \\
\hline 63 & $2(4)$ & 1710 & 351.05 & 58.82 & 1.1 & 39.6 & 263.65 & 83.1 & 176.22 \\
\hline 63 & 3 & 1914 & 334.94 & 71.54 & 6.6 & 60.06 & 263.58 & 76.34 & 168.56 \\
\hline 63 & 3 & 1270 & 353.71 & 67.06 & 3.7 & 55.54 & 267.68 & 83.07 & 123.58 \\
\hline 64 & 2(5) & 1711 & 352.39 & 67.58 & 3.9 & 55.45 & 267.55 & 83.25 & 133.3 \\
\hline 72 & 3 & 1240 & 340.01 & 55.71 & 6.2 & 40.72 & 264.1 & 73.76 & 164.57 \\
\hline 74 & 3 & 2393 & 9.41 & 47.09 & 8 & 43.5 & 5.5 & 73 & 156 \\
\hline 76 & 4 & 2370 & 356.5 & 68.65 & 4.6 & 55.7 & 267.04 & 85.75 & 117.57 \\
\hline 79 & $1(3)$ & 572 & 331.43 & 68.57 & 13.2 & 48.58 & 270.76 & 71.55 & 201.8 \\
\hline 79 & $2(5)$ & 121 & 324.58 & 67.19 & 9.6 & 47.33 & 275.16 & 66.67 & 204.79 \\
\hline 80 & 4 & 2397 & 338.93 & 73.22 & 6.2 & 53.79 & 268.99 & 77.32 & 211.24 \\
\hline
\end{tabular}


Table 2 (Continued)

\begin{tabular}{llllllllll}
\hline Age (Ma) & Dc $(\mathbf{Q})$ & GPDB & Dec & Inc & $\boldsymbol{\alpha}_{95}$ & GLat & GLon & Plat & Plon \\
\hline 81 & 4 & 2382 & 350.99 & 67.72 & 6.6 & 53.84 & 267.94 & 83.64 & 151.61 \\
86 & $2(5)$ & 3037 & 19.94 & 56.93 & 3 & 42.4 & 46.9 & 74 & 148 \\
86 & $2(5)$ & 3037 & 17.76 & 54.02 & 3 & 42.6 & 46.7 & 74 & 161 \\
89.5 & 3 & 1507 & 16.44 & 52.45 & 5 & 51.5 & 8.3 & 68 & 148.99 \\
93 & 3 & 1495 & 2.15 & 57.46 & 4 & 52 & 8 & 76 & 181 \\
100 & 4 & 1322 & 346.92 & 56.49 & 4.4 & 40.85 & 290.76 & 79.15 & 184.5 \\
\hline
\end{tabular}

GPDB = Global Palaeomagnetic Data Base Reference Number; Dc = Demag Code (5 is the best score); Q: Van der Voo (1993) classification factor (7 is best score), listed only for studies with Dc less than 3; $\alpha_{95}$ is the radius of the cone of $95 \%$ confidence; Glat = Site's latitude; Glon = Site's longitude; Plat $=$ Palaeopole's latitude; Plon = Palaeopole's longitude. Site coordinates, palaeopoles and declinations have been rotated into a Eurasian reference frame, using the Euler parameters of Torsvik et al. (2001b).

Table 3 Mean Eurasian reference palaeopoles determined by moving window analysis of 20 Ma at increments of 5 Myr

\begin{tabular}{llllll}
\hline Age (Ma) & $\boldsymbol{\alpha}_{95}$ & GLat & GLon & Plat & Plon \\
\hline 2.5 & 11.43 & 55.91 & 287.6 & 85.75 & 134.72 \\
7.5 & 8.16 & 58.85 & 292.43 & 86.5 & 120.91 \\
12.5 & 7.08 & 56.43 & 285.88 & 86.93 & 109.74 \\
17.5 & 5.15 & 51.26 & 278.76 & 83.33 & 145.17 \\
22.5 & 5.34 & 44.45 & 268.39 & 83.22 & 135.98 \\
27.5 & 4.82 & 45.94 & 271.23 & 81.93 & 139.61 \\
32.5 & 4.57 & 46.9 & 273.05 & 82.17 & 137.74 \\
37.5 & 5.42 & 48.37 & 277.75 & 83.15 & 128.49 \\
42.5 & 3.78 & 58.1 & 301.2 & 81.5 & 138.26 \\
47.5 & 3.26 & 60.39 & 313.39 & 80.35 & 152.74 \\
52.5 & 2.81 & 60.94 & 317.44 & 79.08 & 154.93 \\
57.5 & 2.53 & 62.59 & 316.76 & 78.56 & 156.58 \\
62.5 & 2.88 & 62.29 & 310.09 & 77.86 & 161.81 \\
67.5 & 3.36 & 61.46 & 304.13 & 77.95 & 156.68 \\
72.5 & 4.86 & 274.32 & 79.34 & 175.58 \\
77.5 & 5.73 & 301.73 & 76.95 & 175.72 \\
82.5 & 6.22 & 321.94 & 76.51 & 172.55 \\
87.5 & 6.23 & 66.08 & 12.24 & 75.38 & 177.71 \\
92.5 & 5.72 & 66.63 & 340.41 & 74.73 & 161.78 \\
97.5 & 12.11 & 54.39 & & 75.02 & 166.95 \\
\hline
\end{tabular}

long-term quadrupole fields, but these were deemed less likely than octupole fields because of good agreements between palaeomagnetic and palaeofacies determinations of equatorial positions. They estimated the magnitude of the octupole/dipole field ratio (G3) to be about 0.1 for the $300-40 \mathrm{Ma}$ interval, and suggested that the octupole field may have been responsible for the palaeolatitude anomalies in central Asia, adopting the earlier suggestion by Westphal (1993). In this

Fig. 4 When the value of G3 (the octupole/dipole field ratio) is increased from zero to 0.15 in calculations of the observed and predicted palaeolatitude values, the mean palaeolatitude anomaly diminishes. Error bars are standard deviations.

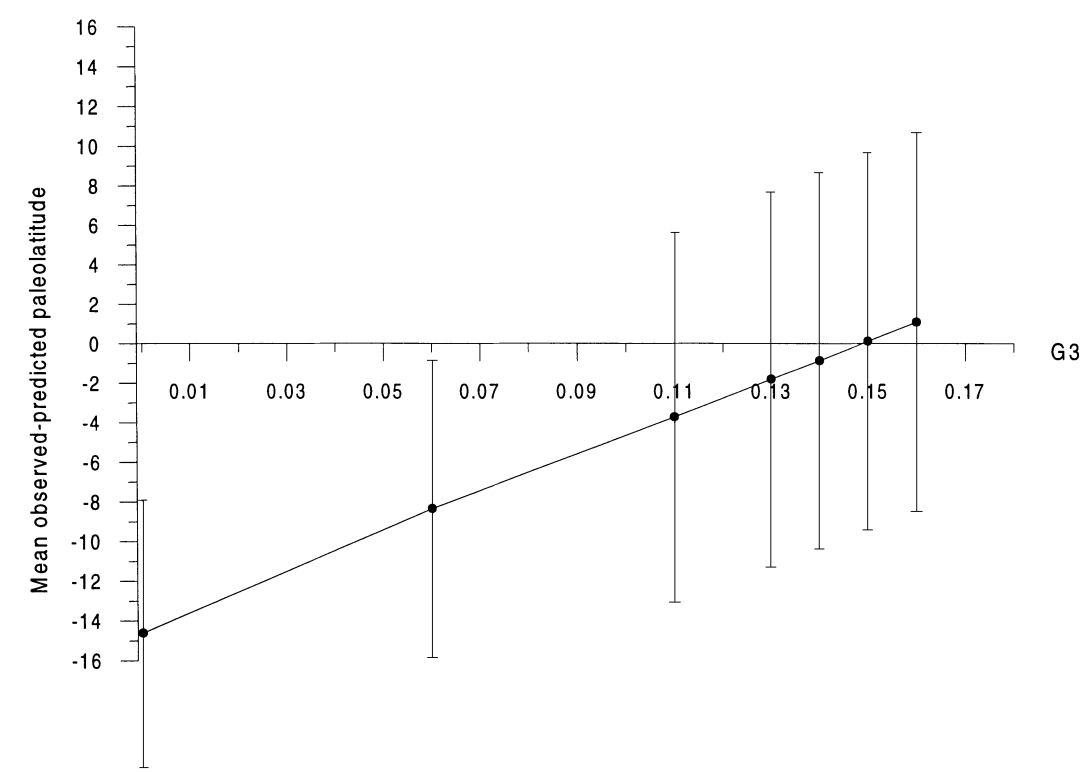


paper, we analyse the available data in terms of the magnitude of possible octupole fields that would be needed to reduce significantly the palaeolatitude discrepancies.

\section{Methodology}

Two datasets have been compiled from the Global Palaeomagnetic Data Base, updated to the year 2000 (Lock and McElhinny, 1991). One set comprises all central Asian 'primary' palaeomagnetic results with demagnetization code 3 or greater, from localities north of Arabia, the Himalayas and Indochina, and south of the Siberian craton and its margins (Table 1), for the interval 80-10 Ma. Results with both a precision parameter $k$ less than 10 and $\alpha_{95}$ greater than $15^{\circ}$ were not included. The localities are contained in the latitude band 20 $50^{\circ}$ and longitudes $40-120^{\circ}$ (Fig. 2). The second set comprises all reliable palaeopoles with either demagnetization code $\geq 3$ (Lock and McElhinny, 1991) or $Q \geq 3$ (Van der Voo, 1993), from the stable parts of the North Atlantic bordering continents for the interval 100-2 Ma, in order to construct a reference APWP. Reconstruction parameters to account for the opening of the Labrador Sea and North Atlantic are from Torsvik et al. (2001b). Table 2 lists the palaeopoles in a European frame of reference. Results from the North American Cordillera and the Pyrenean-AlpineCarpathian belts and further south in Europe were not included.

To test for the effects of octupole contributions, we compare results recalculated for various G3 values between 0 and +0.2 , where G3 is the ratio of the zonal octupole and dipole fields. The best estimate of G3 obtained by Van der Voo and Torsvik (2001) in their analysis of North American and European palaeomagnetic results was about +0.1 , whereas Torsvik et al. (2001a) found that a G3 of 0.08 best explained the hot spot locations in the palaeomagnetic reconstructions of the Atlantic and Indian oceans. The recalculation of an octupole-corrected palaeolatitude value $(\theta)$ is based on the observed inclination $(I)$ in the formula (from equations 6.2.5 and 6.2.6 of Merrill et al., 1998; ignoring a possible quadrupole field):

$$
\begin{aligned}
& \tan I \\
& =\left[2 \cos \theta+\mathrm{G} 3\left(10 \cos ^{3} \theta-6 \cos \theta\right)\right] \\
& \quad\left[\sin \theta+\mathrm{G} 3\left(7.5 \cos ^{2} \theta \sin \theta\right.\right. \\
& \quad-1.5 \sin \theta)]^{-1} .
\end{aligned}
$$

Following the procedures of determining G3 from the data of a single continent (see Van der Voo and Torsvik, 2001), we have attempted to analyse the internal consistency of the Tertiary data from central Asia, by plotting observed vs. internally predicted palaeolatitudes against each other. However, the area comprising all the sites (Fig. 2) does not have a large enough latitudinal extent and the data have too much variation in their observed inclinations to yield a statistically significant plot; nonetheless, the analysis yields a best estimate, albeit not statistically significant, of a G3 value of 0.1 .

More successfully, we have resorted to a second approach, which uses first a comparison between observed palaeolatitudes of the central Asian sites (as calculated with the dipole formula) and
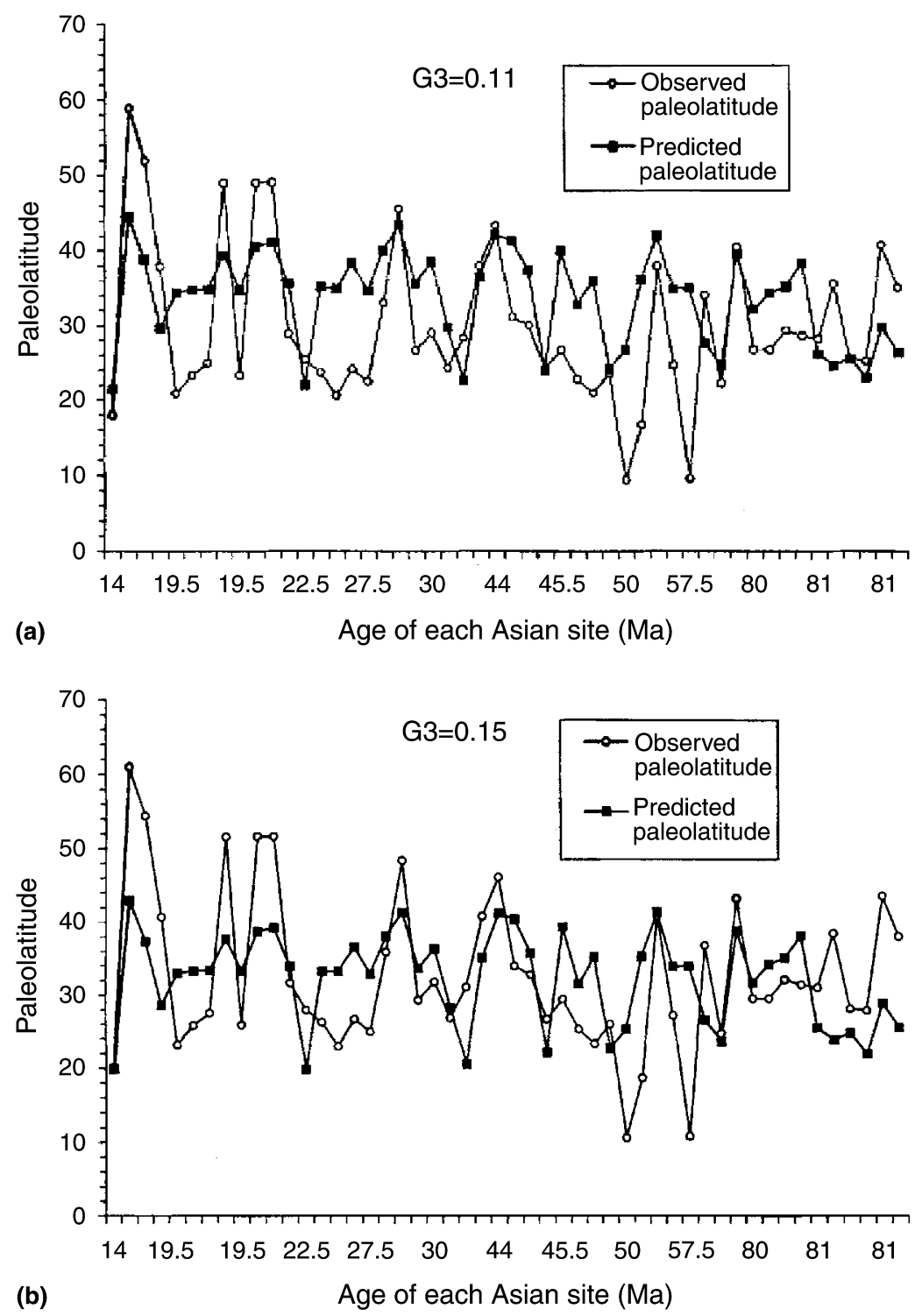

Fig. 5 (a) Observed and predicted palaeolatitudes for the central Asian sites, as calculated with a value of G3 (the octupole/dipole field ratio) of 0.11 . Each result is separately plotted along the horizontal scale as a (non-linear) function of age. (b) Same as (a) but for $\mathrm{G} 3=0.15$. 
palaeolatitudes predicted from the Eurasian reference palaeopoles. Subsequently, both the observed and the predicted palaeolatitudes were adjusted by inclusion of a non-zero G3 in the calculation, using the formula presented earlier. If an octupole field can be held responsible for the palaeolatitude anomalies, we would expect these anomalies to diminish with increasing G3 and to vanish at an optimum $\mathrm{G} 3$ value.

Thus, reference Eurasian mean palaeopoles have been calculated for $\mathrm{G} 3=0$ (Table 3) as well as for $0>$ G3 $>0.2$, using a 20 -Myr moving window at 5-Myr increments. These mean Eurasian palaeopoles are then used to predict the palaeolatitudes for the Asian sampling sites, and these are compared with the palaeolatitudes obtained from the individual studies, which in turn are recalculated for the same G3 ratios as those used for the corresponding reference poles. As expected, the average palaeolatitude discrepancy diminishes with increasing G3 and vanishes for $\mathrm{G} 3=0.15 \quad$ (Fig. 4). There is, of course, variation from result to result in the palaeolatitude anomalies, as can be seen in examples of observed and predicted palaeolatitude sets as shown in Fig. 5 for $\mathrm{G} 3=0.11$ and $\mathrm{G} 3=0.15$.

\section{Discussion}

We have tested the possibility that a non-dipole field, as documented for the 300-40 Ma interval from North American and European palaeopoles (Van der Voo and Torsvik, 2001), can be held responsible for the palaeolatitude discrepancies that are observed in central Asia. We grant that we cannot exclude contributions to these discrepancies from other processes, notably inclination shallowing and - to some extent - relative convergent movements between blocks in central Asia and Siberia or between Siberia and Europe, but argue that all of the latter are unlikely to be of the magnitude to explain the discrepancies in full. Our study demonstrates that a long-term non-dipole field is a viable contender in the array of possible explanations.

In Fig. 4, we see that for G3 $=0.11$, the mean difference between observed and predicted palaeolatitudes (plus or minus its standard deviation) is $-3.72 \pm 9.34^{\circ}$, whereas the mean dif-

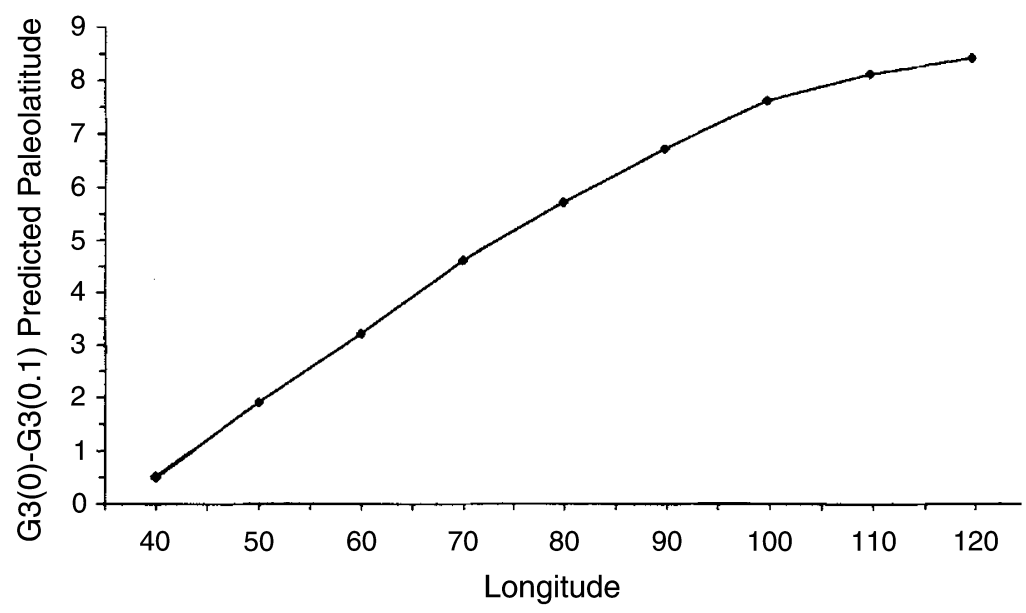

Fig. 6 The differences in predicted palaeolatitudes, as calculated with the geocentric axial dipole formula $(\mathrm{G} 3=0)$ and with a field including a $10 \%$ octupole field contribution $(\mathrm{G} 3=0.1)$, as a function of site longitude in Asia. Palaeolatitudes are calculated from the mean reference results obtained in the North Atlantic domain (Table 3), for sites in central Asia. The difference increases to reach a maximum at a longitude of $120^{\circ}$.

ference becomes zero at $\mathrm{G} 3=0.15$. However, we cannot conclude that the latter value is a better determination of the octupole field than the $\mathrm{G} 3=0.11$ value, for at least two reasons. The first is that the standard deviations overlap with the zero line for the range of G3 values of about 0.06 or greater, and the second reason is that some inclination shallowing and some relative northward movements, although less than the full $1600 \mathrm{~km}$ required by the dipole formula, have likely taken place.

The observation (Chauvin et al., 1996) that the palaeolatitude anomalies increase eastward from the Mediterranean to China is easily explained by the effects of the octupole field on the predicted palaeolatitudes, when using an APWP determined from sites in the North Atlantic domain (Fig. 6). With the mean reference site location centred at a longitude of about $300^{\circ}$ (see Table 3), the largest changes in predicted palaeolatitudes will occur at a longitude of $120^{\circ}$, and will be progressively less at lower longitudes.

\section{Conclusions}

One of the more likely explanations for the large discrepancies between observed and predicted palaeolatitudes in Asia during the latest Cretaceous and Tertiary can be found in the contribution of a long-term non- dipole field to the total time-averaged geomagnetic field. Our analysis yields an estimate of the octupole/dipole ratio greater than 0.06 . This value is about the same as the ratio of $0.05-$ 0.06 in the Oligocene estimated by Schneider and Kent (1990), and is not inconsistent with the Cretaceous Early Tertiary values of about 0.08 and 0.1 , as estimated by Torsvik et al. (2001a) and Van der Voo and Torsvik (2001), respectively. Even though only a ratio of 0.15 can reduce the average palaeolatitude anomaly to zero, we allow that some northward movements ( 100s of km, not 1000s) of the central Asian terranes may have occurred, and that some degree of inclination shallowing certainly cannot be ruled out.

\section{Acknowledgements}

We thank Josep Parés for his advice and encouragement, and the journal's reviewers for valuable suggestions that improved the manuscript. This study is supported by the National Science Foundation, Division of Earth Sciences, grant EAR-9903074.

\section{References}

Besse, J. and Courtillot, V., 1991. Revised and synthetic apparent polar wander paths of the African, Eurasian, North American and Indian plates, and true polar wander path since $200 \mathrm{Ma}$. J. Geophys. Res., 96, 4029-4050. 
Chauvin, A., Perroud, H. and Bazhenov, M.L., 1996. Anomalous low paleomagnetic inclinations from Oligocene-Lower Miocene red beds of the southwest Tien Shan, Central Asia. Geophys. J. Int., 126, 303-313.

Cogné, J.P., Halim, N., Chen, Y. and Courtillot, V., 1999. Resolving the problem of shallow magnetizations of Tertiary age in Asia: insights from paleomagnetic data from the Qiangtang, Kunlun, and Qaidam blocks (Tibet, China), and a new hypothesis. J. Geophys. Res., 104, 17,715-17, 734.

Gilder, S.A., Zhao, X.X., Coe, R.S., Meng, Z., Courtillot, V. and Besse, J., 1996. Paleomagnetism and tectonics of the southern Tarim basin, northwestern China. J. Geophys. Res., 103, 22,01522,031 .

Kent, D.V. and Smethurst, M.A., 1998. Shallow bias of paleomagnetic inclinations in the Paleozoic and Precambrian. Earth Planet. Sci. Lett., 160, 391-402.

Lock, J. and McElhinny, M.W., 1991. The global paleomagnetic database. Surv. Geophys., 12, 317-491.
Merrill, R.T., McElhinny, M.W. and McFadden, P.L., 1998. The Magnetic Field of the Earth. Intern. Geophysics Series 63. Academic Press, London.

Rumelhart, P.E., Yin, A., Cowgill, E., Butler, R., Zhang, Q. and Wang, X.-F., 1999. Cenozoic vertical-axis rotation of the Altyn Tagh fault system. Geology, 27, 819-822.

Schneider, D.A. and Kent, D.V., 1990. Testing models of the Tertiary paleomagnetic field. Earth Planet. Sci. Lett., 101, 260-271.

Tan, X., Kodama, K.P. and Fang, D., 1996. A preliminary study of the effect of compaction on the inclination of redeposited hematite-bearing sediments disaggregated from Eocene redbeds (Suweiyi Fm) from the Tarim Basin, Northwest China. EOS Trans. Am. Geophys Union, 77 (46), F155.

Thomas, J.-C., Chauvin, A., Gapais, D., Bazhenov, M.L., Perroud, H., Cobbold, P.R. and Burtman, V.S., 1994. Paleomagnetic evidence for Cenozoic block rotations in the Tadjik depression
(Central Asia). J. Geophys. Res., 99, $15,141-15,160$.

Torsvik, T.H., Mosar, J. and Eide, E.A., 2001a. Cretaceous-Tertiary geodynamics: a North Atlantic exercise. Geophys. J. Int., 146, 850-866.

Torsvik, T.H., Van der Voo, R., Meert, J.G., Mosar, J. and Walderhaug, H.J., 2001b. Reconstructions of the continents around the North Atlantic at about the 60th parallel. Earth Planet. Sci. Lett., 187, 55-69.

Van der Voo, R., 1993, .Paleomagnetism of the Atlantic, Tethys and Iapetus Oceans. Cambridge University Press, Cambridge. Van der Voo, R. and Torsvik, T.H., 2001. Evidence for Late Paleozoic and Mesozoic non-dipole fields provides an explanation for the Pangea reconstruction problems. Earth Planet. Sci. Lett., 187, 71-81.

Westphal, M., 1993. Did a large departure from the geocentric axial dipole occur during the Eocene? Earth Planet. Sci. Lett., 117, 15-28.

Received 17 July 2001; revised version accepted 24 September 2001 